\title{
¿Hacia una convergencia europea de los modelos de gobierno local? *
}

\section{Vincent Hoffmann-Martinot **}

Evocar la persistencia de los modelos nacionales de gobierno local se justifica, tal y como lo veremos en una primera parte, incluso si éstos han sufrido importantes transformaciones en el tiempo y en el espacio. Al mismo tiempo parece que, después de varios años, los gobiernos locales de los países europeos se ven enfrentados a las mismas posturas prioritarias que a menudo intentan responder de manera convergente. Por lo tanto, en una segunda parte, nos preguntaremos en qué medida los modelos tradicionales tienden hoy a hacerse triviales.

\section{Los modelos tradicionales de gobierno local}

El gobierno de los territorios varía sensiblemente de un país a otro. Más que limitarse a subrayar el carácter idiosincrásico de los diferentes contextos nacionales ( $«$ cada caso es particular»), el comparativista puede y debe pasar a una etapa superior identificando grupos, familias, categorías de casos que correspondan a una misma matriz, obedeciendo a una lógica globalmente común. Por eso, necesitará armarse de conocimientos profundos sobre la historia, las instituciones, las reglas formales e informales del juego político de varios países. De vez en cuando este reto se ha llevado a cabo desgraciadamente de una forma relativamente vacía y descriptiva. Aparte de los trabajos de los juristas (DelCamp, 1997), algunos expertos en política han logrado proponer los fructuosos marcos de comprensión global de la emergencia, de la diferenciación y de la transformación de modelos de gobierno local (HeSSE y SHARPE, 1991;
Hintze, 1962; KJellberG, 1995; Page, 1991; Page y Golds. MITH, 1987; SHARPE, 1970; SHARPE, 1988).

Para evitar previamente toda ambigüedad referente al término polisémico de modelo, precisemos que éste se utilizará en este texto bien como se acaba de definir, es decir, como una categoría, una variedad particular (Muster, en alemán), o bien como un arquetipo, un ejemplo que sirve o debe servir de objeto a imitar (Vorbild, en alemán). La diferencia de significado se debe, por lo tanto, a la variación de capacidad de atracción entre dos usos.

\section{La emergencia de los modelos y su difusión}

La naturaleza y las características de un sistema de gobierno local en un país dado no dependen del azar ni de la sucesión puramente aleatoria de los añadidos, ni de las correcciones, ni de las reformas realizadas en el transcurso de los años. Por el contrario, la historia contemporánea ofrece numerosos ejemplos de Estados que bien se vieron obligados a imponer el sistema de una potencia exterior, o bien se sometieron voluntariamente a un proceso de examen, de comparación, y de selección de los diferentes «paquetes» institucionales disponibles en el «mercado».

La Francia revolucionaria-napoleónica también exportó, con más o menos autoridad, sus instituciones locales desde el Norte hasta el Sur de Europa, aunque bajo el Imperio más de la mitad de los europeos se administraban siguiendo con un mismo patrón de organización uniforme en departamentos, regiones y comunas, bajo la dirección de prefectos y sub-prefectos. Pero si este modelo perdura más allá del reinado de Napoleón, es 
porque se le considera radicalmente moderno, ordenador, racionalizador e igualador. Según ToCQueVLle (1967: 80), «lo que es cierto decir de ella (la Revolución), es que ha destruido totalmente o está destruyendo (porque todavía dura) todo lo que, en la sociedad antigua, emanaba de las instituciones aristocráticas y feudales, todo lo que de alguna manera estaba relacionado con ellas, todo lo que llevara, fuera cual fuera el grado, impresa su huella». Entonces, Francia, ideal de Estado moderno, unificado y unitario, se convierte en la referencia de numerosas naciones. Este país inspira en particular a numerosos responsables políticos alemanes que ante todo desean romper con el pasado multisecular, sus vestigios, sus obsoletas ordenaciones institucionales y políticas, características de una fragmentación territorial extrema (Zersplitterung) (HOFFMANN-MARTINOT, 1997). El mapa de los territorios germánicos de finales del siglo XIX, incluido en el célebre atlas histórico de PUTZGER $(1965)^{1}$, no es nada elocuente desde este punto de vista, ya que representa un extraordinario mosaico formado por múltiples manchas, fragmentos, enclaves correspondientes a ciertos reinos, principados, ducados, obispados, ciudades imperiales libres que entonces constituían el Santo Imperio Romano Germánico.

Varios elementos del modelo francés serán integrados en las instituciones alemanas, tales como la creación de Regierungsbezirke gobernados por los Regierunstpräsidenten y los Regierungsvizepräsidenten, homólogos de los prefectos, o la progresiva desaparición de las provincias que serán sustituidas por una administración territorial con dos niveles (Comunas y Kreise). Pero la era napoleónica, sobre todo, va a generar, por un lado, la unificación progresiva de Alemania gracias a la política francesa de constitución en su zona de influencia de Estados medianos destinados a contrarrestar la influencia prusiana (sobre todo en el Sudoeste) y, por otro lado, incitar a Prusia a pensar de nuevo su sistema político-administrativo siguiendo el ejemplo francés, y particularmente sus instituciones locales. La regeneración y la dinamización del papel atribuido a las comunas a partir de principios del siglo XIX se basaron esencialmente en los conceptos completamente originales de la kommunale Selbstverwaltung del barón von Stein. Este enfoque radicalmente innovador, que indica el camino del despertar democrático de Prusia tras su derrota por parte del ejército napoleónico, vuelve de hecho a combinar y a tratar de sintetizar dos tradiciones existentes. Adopta el modelo francés, rival de sus principios revolucionarios de uniformidad de la legislación, de la ciudadanía (acordada para el conjunto de ciudadanos que posean una propiedad, una profesión o una empresa) y de elección por circunscripción (y no por corporación). Pero, al mismo tiempo, también incorpora elementos de la tradición germánica tales como, en el seno de las autoridades locales, la posición preeminente con relación a la asamblea de un órgano ejecutivo colegial -el Magistrado-, pero sobre todo la importante libertad de acción atribuida a las autoridades locales sobre las cuales sólo se ejerce una tutela estatal relativamente limitada. Esta vuelta a la tradición combinada con una gestión modernizadora pretendía satisfacer y motivar a las fuerzas nacionalistas. Es a partir de esta base Steiniana, expresada en la ordenanza prusiana del 19 de noviembre de 1808 , cuando se pone en marcha la modernización de las diferentes instituciones territoriales alemanas y cuando se diferencian las interpretaciones y las corrientes teóricas. Así, por un lado, nos encontraremos un polo hegeliano encarnado por Rudolf GENIST, después por Ernst FORST. HOFF y Carl SCHMITT, partidarios del fortalecimiento del lugar central del Estado delegando, como garantía de la unidad nacional, una parte de su autoridad a las «unidades locales de la sociedad» y, por otro lado, la esfera de influencia de la Genossenschaftstheorie, representada por Otto GIERKE y Hugo PREU (que niegan toda jerarquía o diferencia esencial entre la comuna y el Estado, y destacan el carácter no simplemente administrativo, sino el propiamente político de las instituciones locales $^{2}$ ).

La amplitud, la rapidez y la duración del proceso de expansión del modelo francés de división y de organización territorial no han conocido equivalente en el resto del mundo y sin duda lo convierten en un fenómeno excepcional, tal como señala VAN. DELLI (1991), uno de los mejores expertos del «transplante institucional». Esta influencia, este magisterio representados por Francia a menudo se han extendido hasta el siglo $\mathrm{xX}$, mantenidos por la difusión de la filosofía y de los principios de la administración y del Derecho público francés ${ }^{3}$ en países retrasados culturalmente. Otra gran zona de Europa (Países Bajos, Bélgica, Estados alemanes, Italia, España, Portugal, Grecia), otros continentes han sido sus receptores, sobre todo en las antiguas colonias francesas de África y también en las espanolas de América latina. En su panorama comparativo internacional, HUMEs (1991) presenta así dos sistemas no europeos de gobierno local derivados del prototipo napoleónico, los de Marruecos y de Colombia.

Dominando durante la mayor parte del siglo $\mathrm{xx}$, el modelo francés ha estado sometido progresivamente a la competencia de otros dispositivos, generalmente más recientes y quizás ellos mismos se hayan visto inicialmente influenciados por los principios revolucionarios napoleónicos. Cuando el gobierno japonés decidió en los primeros años de la era Meiji modernizar sus instituciones locales, éste comenzó en los años setenta a dividir el territorio en un conjunto de prefecturas y de sub-prefecturas. Pero el préstamo del modelo francés no pasó de ahí. En el transcurso de la década siguiente, tras varios estudios oficiales en Berlín y en Viena en los cuales los administrativistas helgianos Rudolf GNEIST y Lorenz von STEIN fueron particularmente consultados y solicitados, el Ministro de Interior Yamagata decidió modelar la organización y el funcionamiento de las colectividades japonesas a partir del ejemplo prusiano, reclutando por un período de cinco años (1886-1891) a un 
experto berlinés formado por GNEIST, que dirigió la elaboración del nuevo Código japonés de las instituciones locales (WICKWAR, 1970: 81-82). De ese modo los japoneses adoptaron en bloque los diferentes elementos constitutivos del gobierno local prusiano: unas asambleas elegidas, aunque un ejecutivo colegial designado por los consejeros, el Landkreis en las regiones rurales, y un sistema electoral desigualitario basándose en una ponderación de las clases sociales en varios colegios. El Gobierno de Tokio manifiesta tan ostensiblemente su voluntad de apertura a las influencias occidentales, y sobre todo europeas, e incluso ayuda ulteriormente a la difusión de este diseño ins. titucional en el este de Asia mientras ocupa Córcega, Taiwan y China...

Un poco más tarde, en el paso del siglo $\mathrm{XIX}$ al $\mathrm{XX}$, otros responsables públicos manifestaron la necesidad de comprender cómo estaban estructurados otros sistemas de gobierno local, los cuales funcionan mejor que el suyo, y en cuyas condiciones algunos de sus elementos serían importables. Se trata de los responsables de las ciudades americanas o de sus asociaciones, tales como la Liga Nacional Municipal. James BRYCE se convierte en el portavoz de los reformadores americanos cuando declara que «el gobierno de las ciudades constituye uno de los fracasos patentes de los Estados Unidos». Su ambición es la de introducir unos mecanismos de gobierno local que permitan conciliar los dos objetivos prioritarios de la democracia y de la eficacia. La buena planificación de las instituciones territoriales francesas seduce a los observadores externos, al menos en apariencia, ya que la extrema centralización parisina ya está cada vez menos adaptada al crecimiento y al desarrollo de otros polos urbanos. La hipertrofia de la capital y de la base político-administrativa que le mantienen, contribuye a acentuar el retraso en cuanto a equipamientos y atractivo global de las ciudades de provincia. Así, los expertos americanos que visitan Europa, y en particular Francia, Gran Bretaña y Alemania, se fijaron en las labores y en las experiencias francesas. Su apreciación es en general bastante crítica, según afirma el comparativista SHAW (1895: 191): «Las principales ciudades de provincia francesas, si está permitido generalizar, tienen mucho más que mostrar al visitante que se siente atraído por los soberbios bulevares, la elegancia arquitectónica, los parques y los jardines bien cuidados, los interesantes monumentos artísticos y otras manifestaciones exteriores de la prosperidad municipal que revelar al investigador que sobre todo se interesa por las aplicaciones de la ciencia sanitaria y por los servicios sociales análogos. Desde este punto de vista, tiene mucho que aprender de las grandes ciudades británicas que, a menudo menos atractivas, han logrado sin duda mejores resultados en lo que se refiere a la distribución del agua pura, la creación del alcantarillado de acuerdo con las prescripciones higiénicas, la salubridad de las viviendas, una política sanitaria y social activa sobre diferentes terrenos.» La siguiente generación, ASHLEY (1921: 94) recuerda esta afirmación que define a las ciudades atractivas como decoraciones turísticas pero bastante deficientes como ambientes para vivir, y lo confirma sin dar muchos matices: «Esto se describió en 1895 , pero sigue siendo verdad, a pesar de ciertas mejoras, y todavía se aplica a las pequeñas ciudades de 15.000 a 25.000 habitantes, donde encontramos con frecuencia museos, bulevares y agradables jardines públicos, pero el agua es malísima y las condiciones sanitarias deplorables.»

Por el contrario, desde finales del siglo xIX hasta la mitad del nazismo, la democracia urbana alemana se convierte en una de las más equilibradas, eficaces y «científicamente» organizadas de los países occidentales ${ }^{4}$. Fascina a numerosas delegaciones de observadores americanos. Para ellos, la superioridad alemana tiende a la coexistencia de tres factores: el desarrollo y el mantenimiento de la red de equipamiento (lo más avanzado del Munizipalsozialismus: agua, gas, canalizaciones), por y bajo el control directo de los servicios municipales, la profesionalización de las burocracias gracias a la selección y al reclutamiento de expertos (cuyos ejecutivos son los alcaldes) y finalmente el alto nivel de autonomía política, administrativa y técnica de las ciudades con respecto a las administraciones estatales ${ }^{5}$. En vísperas de la toma de poder nazi, el experto en política americana Bryn MaWr Wells (1932: 2-3) resume en su obra de referencia los conceptos maniqueos que prevalecen en los comienzos del siglo tanto entre los universitarios como en los procuradores de la gestión pública urbana: «(En Estados Unidos), el gobierno urbano, teóricamente democrático, era con frecuencia poco eficaz, corrupto, dirigido por jefes, y se veía constantemente sometido a las intervenciones legislativas estatales. Por el contrario, en Alemania, donde el crecimiento de la población urbana también había sido extremadamente rápido, el gobierno urbano era eficaz, honrado, sin jefes demagogos, y tenía un grado considerable de autonomía local.» Aunque este «modelo» alemán da lugar a unas evaluaciones más críticas generadas por el declive del reformismo institucional ${ }^{6}$ y por el compromiso de Estados Unidos en la primera guerra mundial, las cualidades fundamentales y ejemplares atribuidas a la figura central del alcalde alemán - su «apoliticismo», y su alto nivel de cualificación - inspiraron directamente a la introducción del sistema del empresario en el gobierno de un creciente número de ciudades americanas. Los viajeros franceses que visitaban Alemania a principios del siglo XX compartían generalmente un mismo entusiasmo, incluso una verdadera fascinación por la planificación y administración de las ciudades alemanas, percibida como radicalmente innovadora ${ }^{7}$. Sin duda lo que más asombró fue la capacidad de las organizaciones municipales para responder a retos de todo tipo originados por un crecimiento urbano mucho más rápido que el de Francia ${ }^{8}$. Evidentemente, el vigor del municipalismo alemán se debía a la conservación de una estructura territorial durante mucho tiempo extremadamente fragmentada y heterogénea y al tardío desarrollo de un Estado modermo centralista. Pero a su vez 
éste se basaba en los efectos de las reformas introducidas por el Barón von STEIN.

\section{Tipología y comparación}

En este punto del debate, se hace necesario precisar lo que tradicionalmente entendemos por «modelo francés de gobierno local». En otras palabras, debemos preguntarnos no dónde reside la «excepción francesa» - porque no existe un modelo que sería más o menos compartido por el resto del mundo y que nuestro país derogaría-, sino más bien cuál es la especificidad del sistema de gobierno local francés. El enfoque más comprensivo que permite comparar de una manera a la vez sistemática y dinámica los diferentes sistemas existentes está basado en los valores fundamentales que les estructuran y les orientan. En particular ha sido formulado y desarrollado por SHARPE (1979) que, después de DupRÉ (1967), considera que todo sistema de gobierno local puede definirse y localizarse en función del significado y de la importancia que éste acuerde según los valores de libertad, de participación y de eficacia. Esta perspectiva analítica tridimensional permite en efecto delimitar, identificar y localizar los principales elementos constructivos de un sistema, y agrupar varios casos nacionales relativamente próximos según estos criterios en categorías más generales, es decir, en modelos (Muster). También se han diferenciado tres modelos dominantes, dada su expansión sobre los diferentes continentes: el modelo francés (y el conjunto de los países, sobre todo del sur de Europa, que lo han importado), el modelo anglosajón (el Reino Unido, Irlanda, Canadá, Australia, Nueva Zelanda y, con reservas, Estados Unidos) y el modelo del norte-centro europeo (Alemania, Austria, Suiza, Países Bajos, Escandinavia) (Hesse y SHARPE, 1991).

El valor de libertad nos vuelve a remitir al grado de autonomía que disponen las colectividades con respecto al Estado. Se trata de una reivindicación clásica de los defensores de las libertades individuales y locales que justifican la existencia y el refuerzo de las instituciones locales debido a la necesidad de limitar la progresión constante de las intervenciones estatales en la sociedad y la existencia cotidiana de individuos, particularmente después del siglo XIX. Este credo liberal, revivificado por los partidarios del Public Choice (elección pública) y del federalismo fiscal, se basa en la presunción de que la colectividad local interpreta y protege naturalmente mejor los intereses de los ciudadanos que el gobierno central, porque sólo ella tiene la capacidad de mantener con ellos una relación de proximidad, de interacciones y de intercambios regulares. Para HAYEK y sus sucesores, la descentralización provoca automáticamente mucha libertad, porque constituye la vía óptima para la revelación de las preferencias individuales. Esta ecuación es problemática y discutible, aunque aquí el término de libertad se debe limitar a las relaciones entre actores públicos territoriales y estatales.

Entonces, nos encontramos con la eterna e irresoluble pregunta sobre la medida de la autonomía de acción del gobierno local en un país con relación a otro. Aparte del interés que suscita en algunos especialistas en ciencias sociales, esta interrogación puede, sin embargo, revestir un significado crucial y muy concreto, si, por ejemplo, nos referimos a los instrumentos de ratings del nivel de «buen gobierno» a los cuales recurren organizaciones internacionales tales como el Fondo Monetario Internacional o el Banco Mundial; un país culto y bien instruido que va camino de la democratización y de la descentralización será elegible para la obtención o la reconducción de una ayuda. Sería científicamente ingenuo pretender dirigir un bit-parade (lista de éxitos) internacional de descentralización, a menos que éste sólo se apoye deliberadamente sobre una dimensión, por consiguiente, rindiendo cuentas de sólo una parte de la realidad. Estimando que «cuanto mayor sea el peso de las colectividades territoriales con respecto al del Estado, más descentralizado estará el sistema», PRUD'HOMme (1994) propone de este modo un indicador global de descentralización exclusivamente basado en datos financieros. De hecho, un «haz de índices» permite diferenciar claramente los tres modelos de gobierno local. El modelo francés es tradicionalmente el más centralizado debido a la estructura piramidal y jerárquica de la Administración pública simbolizada por la tutela, a la importante gama de funciones dispuestas bajo la responsabilidad total o parcial del Estado, y a la fuerte presencia territorial de las funciones estatales. Verdaderamente, los estudiantes de ciencias políticas ya no se dejan engañar por las apariencias institucionales que desde ahora saben descifrar gracias al uso del poder periférico, de la tramitación cruzada, del cúmulo de mandatos y de las redes de políticas públicas. A pesar de estos contrapesos, Francia sigue singularizándose a escala internacional por su alto grado de centralización: menos del $30 \%$ de sus agentes públicos son empleados por una colectividad territorial, contra el $60 \%$ de los países escandinavos y el $70 \%$ de Estados Unidos (APPLETON y HoffMANN-MARTINOT, 1994), el Estado que continúa siendo un actor sectorialmente mucho más preponderante que en los otros dos modelos (principalmente en los ámbitos de la enseñanza, de los servicios sanitarios y sociales y de la policía), capaz por su poder de resistir eficazmente a una persecución de la política de descentralización. Por lo tanto, según la lúcida afirmación de SHARPE (1988: 97): «la razón de ser de las administraciones centrales es la incapacidad funcional de la mayoría de las colectividades locales; como dice el adagio británico: «a los pavos no les gusta la Navidad», y los ministerios tienen un gran interés por el mantenimiento del statu quo...».

Por supuesto, existen dispositivos y sistemas de control del Estado sobre las colectividades locales en Gran Bretaña: un control jurídico tan estricto que, según el principio en vigor, 
las colectividades locales sólo podrán actuar cuando un texto legal les autorice expresamente a ello; un control presupuestario, que ha dado un giro drástico a lo largo de los años cruelmente centralizados del gobierno Thatcher; y un control técnico ejercido por numerosos cuerpos de inspección especializados, sobre todo en la enseñanza y en la seguridad pública. Pero la estructuración de las relaciones entre el centro y las colectividades locales caracterizada por un sistema de gobiemo dual, por una separación relativamente impermeable entre los dos niveles territoriales, se mantiene como la del sistema francés. Igualmente, los Länder alemanes ejercen diversos tipos de control sobre las colectividades locales, en particular a través de sus Regierungspräsidenten; pero, aunque estos representantes territoriales del Estado tienen un papel sensiblemente más eficaz que los prefectos franceses, la justificación de su existencia cada vez se cuestiona más a lo largo de los años. Tan espectacular como haya podido aparecer y ser percibido en su singularidad, el proceso de descentralización puesto en marcha en Francia en los años ochenta está lejos de ser «excepcional», puesto que la mayoría de los países que se ciñen al modelo centro-norte europeo también han conocido, según unas modalidades y ritmos diferentes, importantes cambios de responsabilidades y de recursos en beneficio de sus instituciones locales. De ese modo, entre el 1975 y el 1990, los efectivos de las colectividades locales pasan en Dinamarca de 364.000 a 620.000 ( $+70 \%$, los de Estados Unidos evolucionan de 210.000 a 201.000 , es decir, el $-4 \%$ ), mientras que en Finlandia, en un período ligeramente diferente, de 193.000 en 1970 pasaron a 475.000 en $1990(+146 \%$, los del Estado evolucionan de 176.000 a 213.000 , sea un $+21 \%$ ) (AlBAEK et al., 1996: 35,98 ). El único país occidental que ha adoptado un camino inverso y que todavía constituye en la actualidad «una excepción» es Gran Bretaña, por razones que han sido perfectamente analizadas (SHARPE, 1998; WRIGHT, 1993).

El segundo valor discriminatorio se refiere a la naturaleza y a la configuración de la participación de los ciudadanos en una política local. ¿Constituye ésta y en qué medida un elemento fundamental de tal o cual sistema de gobierno local? Abandonamos la escena de las relaciones intergubernamentales -aunque intervenga en la definición del marco jurídico-ins. titucional- para interesarnos por el perfil interno de la democracia territorial. El modelo anglosajón, siempre en su versión británica, no da nada de importancia a la implicación activa de los ciudadanos en la elección de los políticos locales. SHARPE (1970: 159) lo explica por la imposición de la tradición benthamiana en la evolución histórica del gobierno local, según la cual éste representa «ante todo un conjunto de agencias que proporcionan servicios nacionales de la manera más eficaz posible respetando un cierto número de normas nacionales». En cuanto al comité, MaUd (1967: 68) estimaba que «la administración local de los servicios públicos es esencial, mientras que la elección democrática de los órganos locales de la admi- nistración no lo es». Este concepto general, que hace destacar a la eficiencia del suministro de servicios sobre el compromiso de los ciudadanos y su identificación con una comunidad, parece además haber sido sobrestimado bajo el gobierno Thatcher. El contexto británico evoca, por lo tanto, el de un conjunto burocrático que controla ciertos sectores de políticas públicas relativamente vastas, aunque dotado de una débil legitimidad política que reflejan los niveles particularmente bajos de participación en las elecciones locales. Queda saber si el gobierno laborista actual en verdad pretende invertir esta tendencia burocrático-funcional, tal como lo dejaría suponer el proyecto de introducción de la elección directa de los alcaldes destinada a restablecer el vínculo sustancialmente distendido entre los ciudadanos y los dirigentes municipales.

El lugar concedido a la legitimación democrática, a sus procedimientos, a sus rituales y a sus símbolos está indiscutiblemente mejor anclado en los otros dos modelos, a los cuales debemos añadir el caso de Estados Unidos, que se ha alejado considerablemente de sus orígenes ingleses.

La democracia local está mejor asegurada por el modelo centro-norte europeo que por el modelo cesáreo francés, en particular porque los mecanismos de influencia directa o indirecta del centro que predetermina las posturas y las elecciones están sensiblemente más atenuadas. Otra razón principal tiende al equilibrio interno de los poderes. El modelo francés no es, desde este punto de vista, casi nada progresista, la centralización en beneficio de un líder como el alcalde y el dominio de su mayoría encuentran pocos obstáculos. Esto es justamente lo que temieron y combatieron en Estados Unidos los partidarios del concepto madisoniano del poder, que defendían la división de las competencias y de la influencia para evitar toda desviación monárquica u oligárquica. De ese modo, los reformadores americanos se propusieron en el siglo pasado separar cierto número de funciones de la estructura municipal consideradas como excesivamente sometidas a las máquinas partidistas para confiárselas a las comisiones y comités independientes. Aunque algunos de estos organismos volvieran a entrar posteriormente en el seno municipal, las direcciones que generaron conservaron una relación con la jerarquía más floja que otros servicios. En la mayoría de las ciudades de Estados Unidos, el gobierno de la ciudad, el consejo y el ejecutivo, siguen, por lo tanto, coexistiendo con otras múltiples autoridades independientes, verdaderos Estados en el Estado que a menudo disponen de un poder reglamentario y recursos fiscales propios ${ }^{9}$.

La filosofía de la limitación del poder por un conjunto de mecanismos destinados a fragmentar los organismos públicos territoriales caracteriza igualmente las diferentes variantes del modelo nórdico. Pero la fragmentación se manifiesta en un marco de referencias sensiblemente diferente al de Estados Unidos. Mientras que el proyecto reformador americano, que ha modelado la evolución de una gran cantidad de instituciones terri- 
toriales, tenía como objetivo principal la reducción general de la influencia del político (de las máquinas, de los partidos...) fijando nuevos límites funcionales, territoriales y temporales a su ejercicio, el papel de las instancias políticas no es necesariamente cuestionado ni discutido en las democracias territoriales del Norte de Europa. Dotado de una fuerte legitimidad, si se somete el poder político a un minucioso desglose en los órganos y en los sectores que dirige, es sobre todo para garantizar a las principales formaciones su participación colectiva en la gestión de los asuntos. Esta fragmentación de tipo político está destinada a hacer vivir y trabajar en común a una pluralidad de socios-rivales y, por lo tanto, a invertir el equilibrio existente. Tras su apariencia y su reputación de grupos funcionales altamente consolidados, los gobiernos locales noreuropeos presen$\tan$ en realidad un perfil de liderazgo y de funcionamiento estructuralmente segmentado que caracteriza, según la tipología de LIJPHART (1984), las democracias consensuales. Los mecanismos característicos de estos sistemas políticos pretenden repartir, dispersar y limitar el poder de maneras diferentes. A pesar de la reciente introducción de ciertos mecanismos de tipo parlamentario en el ámbito de las reformas de experimentación llamadas «comunas libres», este consensualismo, favorecido por el principio generalizado de la representación proporcional, caracteriza el total de los países nórdicos. Relativamente cercana, la democracia de concordancia o Proporzdemokratie constituye igualmente el modo de gobierno más difundido en Austria y en Suiza.

También en Alemania, y sobre todo en el sur del país, la regla del consenso domina. Después de cincuenta años, a semejanza de la mayoría de las colectividades territoriales del Bade-Wurtemberg, la ciudad de Stuttgart también está dirigida por un mismo grupo que asocia todos los partidos dotados de una representación mínima, confirmando la «ley de la gran coalición» en vigor en este territorio. Al núcleo central formado por cristianodemócratas, socialdemócratas y liberales, también se han unido tanto los comunistas como los ecologistas. En virtud de una ponderación minuciosa de sus respectivas representaciones, las formaciones gobernantes se reparten según la regla proporcional las funciones de los tenientes de alcalde, de los alcaldes de los distritos, de los altos funcionarios y de las administraciones intermediarias, la dirección de los múltiples satélites municipales en sectores tan diversos como los hospitales, la banca, la vivienda o los transportes colectivos. Sin duda, uno de los efectos positivos de este «reparto pacífico de la influencia ejercida sobre la administración por los diferentes partidos... (es) una atenuación de la lucha partidista» (WEBER, 1980: 358). El reparto de bienes tales como los empleos permite en particular integrar grupos o partidos hostiles o exteriores al sistema político existente.

Sin duda alguna, el ejecutivo elegido directamente por la población favorece por su legitimidad y su propia capacidad de intervención la integración de los diferentes sectores sociales y grupos políticos. Pero la «fuerza» legendaria del alcalde en la Alemania del Sur aparece sensiblemente relativizada por el estricto respeto que éste manifiesta con respecto a las reglas del juego consensual, el cual sólo se permite derogar excepcionalmente por iniciativas políticas personales. Se dan de improviso casos de conflicto entre el primer magistrado y su consejo, aunque rara vez. Al contrario que el alcalde francés, su homólogo alemán no dispone de un aparato político-administrativo propio (gabinete, encargados de misión) y no puede nombrar al teniente de alcalde, ya que el nombramiento de éste está sometido a una lógica de negociaciones y de intercambios entre los diferentes grupos políticos representados en el consejo (Fraktionen). Por consiguiente, la democracia territorial alemana no se parece al gobierno dividido del régimen presidencial americano, ya que ejecutivo y Asamblea están en cierto modo condenados a vivir y a trabajar de común acuerdo. Están motivados por una cultura político-administrativa de la negociación permanente (Verbandlungsdemokratie) y por un cierto número de dispositivos institucionales que aseguran una duración del mandato del alcalde más larga que la de los consejeros municipales, así como una dependencia mutua entre el alcalde -elegido directamente por el pueblo, aunque con frecuencia seleccionado por un partido-y los tenientes de alcalde designados por los grupos políticos.

La eficacia es el tercer valor que permite cualificar a un sistema de gobierno local. Una autonomía local desarrollada supone la existencia de un gobierno local que disponga de recursos suficientes para asegurar lo que puede realizar mejor que cualquier otro dispositivo institucional: un suministro de servicios que las colectividades locales pueden en teoría asegurar óptimamente, por su proximidad con respecto a la población, su capacidad de coordinar las acciones públicas o integrar las diferentes posturas y sus procesos de tratamiento. Hoy al igual que en el pasado, un cierto número de debates ha llevado a poner frente a frente, quizás de forma esquemática, la investigación de la eficacia con la valoración de la democracia, como si estos dos valores fueran exclusivos uno del otro. En el fondo y en numerosos contextos, éstas aparecen más bien complementarias, cosa que por fin parece haber comprendido el gobierno central británico, así como numerosos alcaldes actuales de grandes ciudades que desean favorecer la reconciliación de sus ciudadanos con la política urbana adhiriéndolos estrechamente a la mejora de la calidad de los servicios (CLARK y Hoff. MANN-MaRTinot, 1998). La evolución es desde este punto de vista impactante en Estados Unidos: la discrepancia clásica desde principios del siglo $\mathrm{XX}$ entre los demócratas tradicionales, por un lado, defensores de la política con sus enfrentamientos de clases y de grupos étnicos, sus luchas de partidos y de máquinas, sus conflictos de programas y de ideologías, y los reformistas, por otro lado, que luchan por una gestión pública despolitizada y sin ideologías, sobria, racional y eficaz, que parece 
haberse atenuado considerablemente y haber sido reemplazada por un sincretismo de gestión y de populismo. Los nuevos líderes negros, tales como los alcaldes de Cleveland o de Baltimore, Michael White y Kurt Schmoke, están bien lejos del perfil de activistas militantes de los «campeones de la causa racial» de los años sesenta tales como Coleman Young en Detroit o Marion Barry en Washington, y más bien son «tecnopolíticos» (EISINGER, 1998).

En Europa, el modelo francés tradicional se diferencia de los otros por la importancia menor que atrae a la eficacia. Tal como hemos visto previamente, en el modelo anglosajón, sobre todo en el británico, las colectividades locales se consideran ante todo como órganos de prestación de servicios colectivos, y según la mayoría de los observadores en una medida completamente insuficiente, como espacios políticos y democráticos. Por el contrario, el modelo centro-norte europeo pretende fundamentalmente ejercer simultáneamente estos dos papeles. En un sistema político nacional dado, el revelador sin duda más manifiesto y más pertinente del significado atribuido a la eficacia es la actitud global y la estrategia adoptados frente a la postura de las pequeñas colectividades territoriales privadas de autonomía real. Los análisis, debates y reformas fracasados y logrados se han sucedido en la Europa del Oeste desde 1950 hasta 1970 (DENTE y KJELLBERG, 1988), antes de ser reanudados en las nuevas democracias de Europa oriental desde principios de 1990. Los países del sur de Europa, los más influenciados por el modelo de gobierno local francés (Francia, España, Grecia, Italia), han conservado después de cuarenta años la misma estructura territorial caracterizada por una fragmentación extrema. En estos Estados, la mayoría de las comunas están moribundas o se mantienen artificialmente con vida gracias a las ayudas exteriores, en virtud del respeto de las «células de la democracia».

\section{II. ¿Hacia una convergencia de los modelos?}

Según numerosos estudios publicados en Europa en el transcurso de los últimos años, que fluyen del medio académico o profesional (Crédito Local de Francia, Instituto de la Descentralización, prensa especializada), la evolución contemporánea de las colectividades locales obedece a las mismas tendencias globales en el conjunto de los países occidentales, aunque las diferencias observadas de un país a otro se harían cada vez más secundarias. Las mismas causas producirían los mismos efectos, contribuyendo a una homogeneización progresiva de los modelos de gobierno local preexistentes. Este tipo de razonamiento y de argumentación necesita, no obstante, ser revi- sado, a causa de la diversidad de las historias y de las culturas político-administrativas de los países considerados condicionando los modos de reacción y de adaptación eminentemente variables según las pesadas tendencias de transformación. En otras palabras, más que repetir hasta la saciedad la tesis no verificable por la geometría muy variable de la sustitución ineluctable y universal del gobierno por la gobernación, nos preguntaremos en qué medida el modelo tradicional se aparta actualmente de sus características originales para eventualmente ceñirse a otros dispositivos.

Aunque se observe en diferentes partes del mundo, la deseen o favorezcan numerosos expertos, gobiernos estatales, organizaciones internacionales o miembros del servicio privado y asociativo, la convergencia contemporánea de los sistemas de gobierno local, calificada de gobernancia o de nueva gestión pública de empresas, se traduciría en términos esquemáticos e ideales en más descentralización, menos fragmentación y más democracia.

\section{El proceso de descentralización}

Tal como lo hemos indicado previamente, las reformas francesas de descentralización han entrado en un movimiento iniciado a partir de los años cincuenta que engloba el conjunto de los paises europeos, con la destacable excepción de Gran Bretaña. Esta acción descentralizada, por lo tanto, ha incrementado la complejidad de los circuitos de decisión territoriales resultantes del amontonamiento de los niveles de competencias. La ausencia de definición mínima de un reparto de responsabilidades entre colectividades territoriales se manifiesta cotidianamente en la multiplicación de iniciativas concurrentes y no coordenadas destinadas a un mismo territorio y por el uso desenfrenado de las financiaciones cruzadas. De este modo, MalibeAu (1991) subraya que «la necesidad (de una cierta colaboración) es funcional siempre que el sistema esté fragmen. tado al máximo por la multiplicación de sus estructuras, que no haya jerarquía formal entre sus diferentes niveles donde incluso se encuentren dos series de colectividades intermediarias (departamentos y regiones)». La configuración actual de las responsabilidades se caracteriza también por un alto nivel de opacidad donde se pone de manifiesto la incomprensión generalizada entre los franceses ante el embrollo existente en la fiscalidad local (en el otoño de 1996, el $90 \%$ de los contribuyentes locales interrogados pensaban que el producto de los impuestos locales volvía en su totalidad a las comunas ${ }^{10} \ldots$.).

La desjerarquización de las relaciones intergubernamentales caracteriza la mayoría de los países occidentales. Sea unitario, federal o federado, el Estado de las democracias contemporáneas prácticamente no puede actuar como soberano imponiendo sus elecciones y sus políticas a los otros actores públicos. 
Sus intervenciones están mucho menos guiadas por el orden formal que por la preocupación de impulsar o de propulsar, de incitar y de coordinar. Entre las causas principales de esta profunda mutación, los límites objetivos del proceso de extensión del Estado-Providencia se manifiestan después de quince años por la disminución del crecimiento económico y el enrarecimiento resultantes de los recursos públicos nacionales. El Estado, por lo tanto, se ha visto progresivamente forzado a someterse, claro que de una manera negociada, al respeto de los principios y de las normas fijadas a un nivel supranacional, en particular en el ámbito europeo. Sabemos cómo tanto el gobierno francés como las autoridades de Bonn vigilan celosamente para proteger sus prerrogativas y para defenderse de la competencia ejercida por las regiones y los Länder en sectores tan sensibles como las ayudas europeas para el desarrollo económico y regional.

La competencia del Estado en calidad de generalista reputada por encarnar el «interés general» se opone, por lo tanto, a la diferenciación y a la complejidad de las posturas públicas. Intentar aportar soluciones a los departamentos con dificultades, reformar el sistema de enseñanza, elaborar planes de desarrollo de los transportes, reconvertir los sectores económicos, imaginar mecanismos de integración de las minorías étnicas, tantos ejes de políticos públicos como necesite la puesta en común de las informaciones, de recursos y de estrategias compartidos por una pluralidad de miembros. Ahora bien, en cuestión de sólo unos años, se constata en la conducta de numerosas políticas públicas territoriales que el liderazgo reivindicado hace mucho tiempo, ejercido por el Estado a través de sus diversos componentes y globalmente aceptado por los socios, ha sido sustituido por un sistema de acción policéntrica en busca de un nuevo equilibrio. Al igual que las mentalidades se adaptan al nuevo orden (o desorden) mundial que ha sucedido a la tradicional discrepancia entre el Este y el Oeste, en varias ocasiones observadores y expertos piden actualmente más o menos explícitamente el regreso de un Estado potente. Este deseo, en realidad, se traduce en muchos casos en la nostalgia de un pasado apenas lejano donde el Estado ocupaba un lugar regulador preponderante negociando con los representantes del sistema notabiliario.

Por sorprendente que parezca, ya que es a menudo difícilmente descifrable, el nuevo contexto de la acción pública presenta al menos las ventajas del punto de vista de la democracia que se caracteriza por un grado más alto de división del poder. Consciente de la necesidad, más afirmada que antaño, de repartir las responsabilidades territoriales para lograr un acercamiento más consensual del tratamiento de los problemas y de la implantación de las políticas, en lo sucesivo el Estado coopera más que opera. Regula más que realiza. No está en posición de intervenir masivamente a través de una política de compensación de las disparidades socioeconómicas y territoriales por tres razones:
- la inadecuación de estos programas nacionales insuficientemente diferenciados y dirigidos respecto, por una parte, a sus conflictos de reparto de la riqueza que se van acentuando cada vez más y, por otro lado, a sectores o decisiones y acciones de una constelación de actores no han cesado de entremezclarse en el transcurso de los años. Esta densidad de interdependencias institucionales hace cada vez menos probables y en todo caso cada vez más arriesgadas las iniciativas tomadas en solitario;

- la escasez de recursos financieros a su disposición;

- la debilitación de la legitimidad del Estado todopoderoso debido a una evolución general de los valores de ciudadanos cada vez más distantes con respecto a las organizaciones jerárquicas tradicionales.

Este Estado «más modesto», más por obligación que por elección, se manifiesta en particular a través de nuevos procedimientos territoriales elaborados a escala regional. Así, tanto en Francia como en Alemania o en Suiza, éstos revelan un perfil bastante similar. La búsqueda prioritaria de un consenso se basa en la asociación al proceso de negociación y de decisión de un gran número de participantes que representan las categorías principales de interés preocupadas por los proyectos, un enfoque pragmático, público y profundo de las posturas en discusión, así como la ausencia de jerarquía entre los diferentes socios implicados, pudiendo quedar relegado el Estado al simple papel de notario registrando los acuerdos, desacuerdos y medidas preconizadas o adoptadas. Este modo de funcionamiento justifica que ciertas comunidades regionales de decisión se hayan podido calificar de Policy-Landsgemeinden ${ }^{11}$. Por lo tanto, a pesar de este movimiento político-institucional fundamental de descentralización que hace que Francia se asemeje indiscutiblemente a la mayoría de los países occidentales, la estructura nacional del reparto de la producción, riquezas y equipos sigue siendo una de las más concentradas. Con un censo entre la unidad urbana parisina y la que la sigue, la región leonesa, de 7.4, Francia siempre mantiene el récord de Europa. La macrocefalia de París, que se traduce en una concentración del $26 \%$ de la población urbana en su seno, no tiene equivalente en Europa. El dominio de la capital francesa sobre su territorio nacional no es simplemente demográfico, sino también económico (el $90 \%$ de las sedes sociales de las empresas francesas, así como de su cifra de ventas) y cultural. Sin duda, después de los siglos no podemos cambiar fácilmente un país modelado por la centralización, sobre todo mientras sus personalidades político-administrativas parisinas no vean ninguna razón para ir más allá de las leyes...

\section{Reducir la fragmentación}

La tendencia a la fragmentación de las colectividades territoriales contemporáneas es un fenómeno significativo siempre 
y cuando ésta cuestione la estructura consolidada que caracterizaba tradicionalmente las organizaciones públicas locales del continente europeo. Cara a las nuevas posturas - tales como la importancia incrementada de las externalidades, de la segregación socio-espacial, del desarrollo económico y de la protección del medio ambiente - que justifican aún más que antes los comportamientos y prácticas de cooperación, el gobierno territorial se encuentra por el contrario sometido a un proceso global de fragmentación contribuyendo a fragilizar sustancialmente la legitimidad de su acción.

A pesar de los límites inherentes a todo ejercicio de este tipo, las principales reformas del sistema público territorial occidental puestas en marcha en los años 1960 y 1970 tenían como objetivo reducir la fragmentación territorial. A diferencia de Francia, los resultados registrados en los países de Europa septentrional y en la RFA fueron sustanciales, ya que la mayoría de las colectividades territoriales más pequeñas fueron reagrupadas. Pero esta vaga racionalización sólo fue uno de los episodios de una amplia gama de tentativas más o menos logradas de concentraciones parcelarias territoriales. Así que en Alemania, desde finales del siglo XIX hasta la caída del nazismo, las aglomeraciones urbanas no han cesado de verse sometidas a movimientos de modificación del trazado de sus fronteras y de sus delimitaciones internas, dirigidos por los servicios encargados específicamente de su elaboración y de su ejecución, los directores de la extensión urbana (Stadterweiterungsämter).

La discusión sobre la fragmentación de las fuerzas territoriales ha resurgido recientemente. En primer lugar, varios países occidentales se habían mantenido al margen del movimiento reformador que se había concretado hacía veinte años. Por supuesto, estamos pensando en Francia, donde numerosas voces que emanan tanto del mundo político como del sector económico o asociativo hablan en favor de reagrupamientos supuestos para facilitar la reactivación de miles de comunas rurales moribundas y asegurar una reducción de la incoherencia de las políticas de las regiones urbanas. Se trata de la tasa profesional de aglomeración o de la renovación de la fórmula de las comunidades urbanas, las iniciativas localizadas y los proyectos de experimentación o de reforma global manifiestan una nueva voluntad para reformar el mapa territorial. Es igualmente una postura central de reconstrucción de las instituciones democráticas en los países de Europa central y oriental que inicialmente han elegido la vía del statu quo con el fin de restaurar la sustancia de las identidades locales, medianamente maltratada durante décadas por los regímenes comunistas. Pero este reaprendizaje del funcionamiento de las unidades básicas de la democracia suscita al mismo tiempo la toma de conciencia de posturas cuyo impacto territorial invada las fronteras legadas por la historia. El contexto es sensiblemente similar en los Länder de Alemania oriental que formaban la ex RDA. Tienen casi tantas comunas como la parte occidental mientras que su pobla- ción es prácticamente cuatro veces menor. Pero se benefician de un aporte sustancial de experiencias y evaluaciones comparativas proporcionado por los procuradores y expertos de los Länder occidentales, cuya asistencia concreta y masiva en el marco de los padrinazgos y hermanamientos concertados desde los primeros meses de unificación se revela determinante. Por otro lado, las posturas asociadas a la fragmentación territorial han tendido a exacerbarse en los últimos años en la mayoría de las regiones urbanas occidentales, dando lugar a la metropolización de un gran número de problemas municipales y a la reactualización de las perspectivas de reforma institucional casi abandonadas desde finales de los años setenta. La naturaleza de las posturas ha evolucionado. La búsqueda del óptimo dimensional para la gestión de los servicios públicos locales en el marco de una modernización integrante de las acciones del Estado y de las colectividades territoriales ya no es la preocupación central. Por el contrario, las fórmulas de cooperación más o menos integradas establecidas en los años 1960-1970 ponen de manifiesto sus insuficiencias en la regulación de posturas que cada vez se hacen más conflictivas, tales como la planificación urbana, el desarrollo económico, la acentuación de las disparidades socioeconómicas, la gestión de los grandes equipamientos colectivos, o la protección del medio ambiente. Las comunidades urbanas francesas, al igual que las Regionalverbände alemanas, sufren las consecuencias de ejercer competencias sobre territorios actualmente superados por la extensión de las regiones urbanas y puede que no estén dotadas de una legitimidad supracomunal que permita solucionar los conflictos y los bloqueos provocados por la afirmación de los diferentes intereses comunales representados.

Por otro lado, la multiplicación de las instituciones que intervienen en un territorio ha contribuido a acentuar un fenómeno distinto pero estrechamente correlacionado, el de la fragmentación interna de los gobiernos territoriales. A la diferenciación progresiva de las tramitaciones técnicas o de los programas de financiación estatal ha respondido la constitución y la autonomización de agencias y de servicios territoriales; las dos tramitaciones tienden a desarrollar una densa red de intercambios $y$ de interacciones basada en una formación semejante o idéntica, una movilidad entre ellas organizada por pasarelas, una cultura y Weltanschauungen comunes, y un trabajo cotidiano de cooperación.

La fragmentación funcional interna puede obedecer, por tanto, a otras lógicas como la de la homotecia estimulada por el desarrollo de los intercambios con las administraciones estatales sectoriales. La diferenciación de las posturas socio-políticas favorece así la prosecución del movimiento de larga duración de burocratización y de especialización, aunque éste adopte hoy nuevas formas, como, por ejemplo, una asociación más estrecha entre los sectores público y privado. Pero este «avance ineluctable de la burocracia» genera por sí mismo sus propios lími- 
tes, más o menos subestimados o eliminados deliberadamente por WEBER ${ }^{12}$, y sobre todo la tendencia a la constitución de subsistemas relativamente autónomos, verdaderos «islotes de poder funcional».

Uno de los principales factores de la fragmentación ha sido desde 1980 la aplicación en numerosos países occidentales de programas de privatización. Este movimietno de gran amplitud, favorecido a su vez por la acentuación de las tensiones financieras y por el incremento de las tesis neoliberales, contribuye a transformar más o menos radicalmente según el país y los tipos de organizaciones públicas el funcionamiento de los sistemas político-administrativos territoriales. Con más frecuencia, los gobiernos territoriales han inyectado privatización no masivamente, sino de una manera relativamente dosificada, inspirándose en la gestión de las empresas más que calcándola. El kit conceptual e instrumental de los directores territoriales también se ha hecho bastante semejante entre las naciones. Llamado a menudo gestión pública (New Public Management, Neues Steuerungsmodell), se basa principalmente en la idea de que actualmente el gobierno debe comportarse de manera más empresarial que intervencionista, regular más que administrar (steering not rowing role), abstenerse lo más posible de hacer limitándose a mandar hacer (enabling autbority), comprometerse prioritariamente en función del rendimiento a alcanzar y no de las inversiones a realizar, adoptar una gestión comercial con respecto a los usuarios/clientes, favorecer el cambio de mentalidades y de estructuras adoptando reglas y procesos del mercado. Los caminos explorados después de más de diez años en esta línea del «hacerlo mejor con menos» son múltiples y van desde la concesión a la introducción de la competencia entre distribuidores públicos y privados, pasando por la planificación y la gestión preventiva.

Bajo el efecto del desarrollo de las agencias especialistas y colaboraciones público/privado, la evolución reciente de las administraciones municipales francesas y europeas recuerda extrañamente la tendencia a la balcanización de las organizaciones bien conocida en Estados Unidos. Copiando al poderoso líder del Port Autbority of New York que, según Lewis Mum. FORD, fue «la persona que ejerció más influencia en el siglo XX sobre las ciudades americanas» (citado por CARO, 1974: 12), los responsables de las desarticulaciones territoriales reinan como amos en sectores enteros de la política urbana. En términos un poco alarmistas, LowI (1987: 259-260) ha denunciado el poder exorbitante de estos «nuevos aparatos»: «ningún alcalde de una ciudad moderna tiene los medios para saber con exactitud si los "jefes" de los nuevos aparatos (los jefes de negociado y los altos funcionarios de carrera) sólo se mostrarán leales con la agencia, sus labores y sus reglas profesionales. Nuestros alcaldes modernos se encuentran casi en la misma situación que el presidente del Consejo de la Cuarta República Francesa que, en la Asamblea Nacional, debía enfrentarse a toda una gama de partidos intransigentes». En un informe bastante pesimista, YATES (1997) considera que las ciudades americanas están cada vez más sometidas a un pluralismo de lucha callejera (street-fighting pluralism) caracterizado por la diversidad, la variabilidad, la complejidad, la inestabilidad y la interdependencia de los intereses y de los juegos de decisión favorecidos por un alto grado de fragmentación de las burocracias municipales.

Precisamente por esta razón, asistimos desde principios de 1990 a unas nuevas experiencias institucionales destinadas a reforzar un liderazgo público territorial siendo frecuentemente consciente de su estado de fragmentación y de la tendencia a la dilución de sus responsabilidades. En varios países, se han estudiado unas pistas con el fin de encasillar a un «jefe», de acuerdo con la definición de MerTON (1965: 126): «la función clave del jefe consiste en organizar, centralizar y mantener en condiciones de mercado las «parcelas de poder diseminadas» presentes en toda nuestra organización política. Con esta centralización del poder político, el jefe y su aparato pueden satisfacer las necesidades de varios subgrupos de la comunidad». La postura es considerable, en particular en las grandes ciudades, donde no sólo se trata de reforzar el poder de integración del alcalde, sino también de acrecentar su legitimidad. El perfil del alcalde francés tradicional, dotado de una influencia a menudo desmesurada, sirve por este motivo tanto de referencia positiva como negativa. Las diferentes reformas en curso o ya puestas en marcha en Europa pretenden, por un lado, dotar al alcalde de fuerza y de una representatividad política suficientes para permitirle negociar con éxito a nivel estatal e incluso, más generalmente, a escala extramunicipal, con el fin de ser considerado como un líder representativo; por otro lado, conseguir una fuerte legitimidad, testimonio de movilización y de participación activa de la población, asegurándose una posición de líder político; y finalmente alcanzar un status de profesional eficaz de la administración y de la gestión pública, capaz de dirigir la asamblea compleja y polimorfa de la burocracia municipal en calidad de líder organizacional (DELGADO, LÓPEZ-NIETO y LÓPEZ, 1998: 238-252).

Instaurar al alcalde como líder representativo principal de la ciudad, portavoz o agente del conjunto de sus intereses en las negociaciones con los ministros y el colectivo de miembros externos a la municipalidad, su compañero natural en la negociación de grandes proyectos, constituye uno de los proyectos fundamentales de descentralización del gobierno de Tony Blair en Gran Bretaña. Las ciudades británicas tienen en efecto un problema de identidad y de liderazgo políticos que se ha podido interpretar legítimamente como uno de los factores de su incapacidad de reaccionar y de resistir con eficacia al crecimiento recentralista dirigido en los ochenta por la ex Primera Ministra Margaret Thatcher. Con el fin de resurgir políticamente, de volver a equilibrar su influencia y su capacidad autónoma de acción y de decisión respecto a un gobierno central hecho omni- 
presente, las ciudades deben ser capaces de exhibir y afirmar sus perfiles específicos y de visibilizar sus políticas mediante un «alcalde estándar», cuya misión será federar y defender los intereses de su ciudad en el exterior. El próximo alcalde de Londres encarnará esta completa mutación del alcalde británico, tradicionalmente encasillado en un papel representativo de segundo plano con respecto a la preeminencia de la asamblea municipal y del ejecutivo administrativo.

La introducción de un sistema de alcaldía es, por otro lado, considerada por los reformadores como un instrumento eficaz de reactivación de la democracia en las grandes ciudades, gracias a una dinamización del papel del líder político del alcalde. Los mecanismos de intercambio y de interacción regulares entre ciudadanos y responsables públicos se han hecho cada vez más complejos de asegurar en estos sistemas políticos territorialmen. te y demográficamente vastos y socialmente heterogéneos. Aquí y allá, gobiernos y Parlamentos han debido tomar consciencia progresivamente de la necesidad fundamental experimentada por más y más individuos: éstos desean ante todo más claridad en la identificación y en el control democrático de los principales responsables de las políticas dirigidas. Desde 1978, Israel ha elegido romper con esta lógica de opacidad inducida por un sistema de partidos hiperfragmentado haciendo elegir a los alcaldes mediante el sufragio universal. Persiguiendo el mismo objetivo de responsabilidad de los gobiernos urbanos, el Parlamento italiano ha adoptado en 1993 una ley permitiendo desde ahora la elección directa de los alcaldes por la población en las comunas de 15.000 habitantes, e incluso otorgándoles competencias importantes en las ciudades de más de 100.000 habitantes, el derecho de constituir ellos mismos su «gobierno», la junta, nombrando adjuntos no procedentes de los rangos del consejo municipal. Más allá de los casos israelí e italiano, la elección directa del alcalde tiende a ser considerada como un mecanismo de «modernización» de la política urbana, acercando el ejecutivo al pueblo, por una personalización facilitada por campañas electorales altamente mediatizadas y por el marketing político practicado por las organizaciones políticas de las alcaldías. El papel, la fuerza y las perspectivas de los partidos políticos, por lo tanto, se encuentran considerablemente modificados; el carisma o la habilidad políticas de un individuo cuentan mucho más que la ideología, los programas o las estrategias de las formaciones partidistas de antaño. En Estados Unidos, la decadencia regular de la funcionalidad de los partidos políticos como «máquinas» que alimentan el clientelismo ha hecho cada vez más obsoleta la línea tradicional de oposición entre ciudades no reformadas y ciudades reformadas (suspensión de funciones de los partidos y ejecutivo despolitizado confiado a un gestor de ciudad o city manager), aunque la elección del alcalde, convertida en un instrumento de democratización y sobre todo de representación de las minorías socialmente desfavorecidas, de nuevo se ha generalizado desde 1960 y hoy concierne al $90 \%$ de los municipios de más de 100.000 habitantes.

En el contexto contemporáneo de creciente fragmentación de la acción pública municipal, el alcalde se presenta, finalmente, en calidad de líder organizativo situado en el cruce de caminos y en la cúspide de los diferentes sectores políticos administrativos, como el único actor que puede asegurar una cierta integración de los programas y de las políticas. La inestabilidad y la parcelación acentuadas de los equipos político-administrativos de dirección, que a menudo retrasan o bloquean los procesos de decisión, hacen cada vez más necesaria la intervención no de una de las ex máquinas, sino de una autoridad políticamente legítima capaz de trazar orientaciones fundamentales y de facilitar las elecciones indispensables antes de ponerlas en marcha. El alcalde puede y debe jugar este papel de mediador, de conciliador y de guía: es en todo caso uno de los fundamentos de las reformas sugeridas actualmente en Gran Bretaña, donde la multiplicación de las bung autborities, estas ciudades caracterizadas por la ausencia de mayorías claras en el seno de la asamblea, hace urgente una transformación de los acuerdos institucionales existentes. Semejante reestructuración de envergadura se decidió en Alemania en el transcurso de los años noventa con la difusión progresiva y generalizada, en la totalidad de los Länder, del modelo de alcalde procedente de los Estados del Sur (piedra angular de la organización municipal, el alcalde de Baviera y del Bade-Wutemberg es elegido directamente por la población y dispone de sustanciales recursos de acción). Una parte de los reformadores defienden igualmente una adaptación de las instituciones urbanas a la evolución contemporánea de las posturas y de las escalas de acción pública condicionada por la metropolización, introduciendo gobiernos de aglomeración o de región urbana más integrados que las estructuras intercomunales existentes, gobernados por un ejecutivo elegido directamente por los habitantes de este espacio (semejantes a los prototipos de Stuttgart y de Londres). De ese modo se confirma y se precisa el proyecto de responder a las crecientes fuerzas centrífugas que amenazan la viabilidad de los gobiernos de las grandes ciudades creando o reforzando la posición de coordinación y de dirección organizativas del alcalde. El perfil académico y profesional de éste evoluciona, en consecuencia, hacia una profesionalización más profunda haciendo poco compatibles el cúmulo de otros mandatos polí. ticos, y sin esperar la adopción de la reforma gubernamental que pretende «modernizar» la vida política, la práctica de la mayoría de los alcaldes franceses de grandes ciudades elegidos en 1995. En abril de 1997, veinticinco de los treinta alcaldes de las grandes ciudades francesas que cuentan con más de 100.000 habitantes encarnaban, en efecto, una evolución de las prácticas y de las lógicas de la profesión: diez no ejercían ningún otro mandato electoral, otros seis ocupaban un escaño en un consejo general o regional, y nueve desempeñaban a la vez funciones en el Parlamento francés o europeo. 


\section{Reorganizar la democracia territorial}

En todos los países occidentales, la revalorización del papel del ciudadano en la política local es defendida por la mayoría de los reformadores (Gabriel y Hoffmann-MaRTinot, 1999). Según los «demócratas fundamentalisas», la historia contemporánea de la política territorial se resumiría en una confiscación del poder por un puñado de personalidades: el Estado, los notables, la oligarquía parisina, los que toman las decisiones económicas, o bien los tecnócratas. Bastaría desde ese momento «dar la palabra a los habitantes» para cambiar radicalmente las reglas del juego multiplicando el número de actores efectivos. Este argumento se desarrolla a menudo con un cierto angelismo, oponiéndose una democracia directa colmada de virtudes a una democracia representativa retrógrada. Pero el ritmo de estos demócratas radicales puede esconder otro, el cada vez más frecuentado por aquellos que acostumbramos a llamar nimbysts desde hace unos años, partidarios del «en mi jardin no», del repliegue por la defensa de intereses estrechamente circunscritos tanto a escala territorial como social: este neoconservacionismo lo manifiestan tanto las gated communities, que se multiplican en Estados Unidos, como las estrategias regionales secesionistas (Liga del Norte en Italia) o aislacionistas (Baviera en Alemania). La llamada del individuo -contribuyente, usuario y ciudadano - también ha sido el centro de la estrategia del gobierno conservador británico que pretende debilitar al máximo los «cuerpos intermediarios» que encarnaban con bastante poder, según la señora Thatcher, las administraciones territoriales, los sindicatos y las organizaciones vinculadas con los laboristas.

Pero más allá de estas reivindicaciones y olas populistas, la tendencia al refuerzo de los mecanismos de asociación de los ciudadanos tiende a generalizarse y a institucionalizarse progresivamente, modificando más o menos sensiblemente la estructura de los tres modelos principales de gobierno local (sobre el refuerzo de la democracia inframunicipal en España, ver Rodríguez Álvarez, 1996). Sean cuales sean las reservas que podamos formular con respecto a su voluntad real de cambio ${ }^{13}$, éste es en todo caso el objetivo implícito del nuevo gobierno Blair, tal como ha sido presentado el 30 de julio de 1998 por el viceprimer Ministro John Prescott en un libro blanco sobre la «revitalización» de las ciudades británicas. Tanto en Alemania como en Gran Bretaña, el declive a menudo impresionante de la participación electoral —cuyo nivel parece aproximarse cada vez más al de las grandes ciudades de Estados Unidos, donde en la actualidad sólo un elector inscrito de cada cuatro participa en el escrutinio municipal- explica sin duda en parte la movilización gubernamental y parlamentaria a favor de una diversificación de la expresión de los ciudadanos. En el transcurso de los últimos años, la mayoría de los Länder también han introducido la elección directa de los ejecutivos locales y facilitado el desencadenamiento de referéndums e iniciativas populares.

Si en algunos países uno se puede preguntar sobre el bien fundado carácter democrático de esta corriente reformadora populista, asimilable a un prurito de democracia directa, su progreso parece más indispensable en Francia, ya que los ciudadanos han sido observados durante mucho tiempo con recelo y a distancia por los equipos políticos dirigentes y las burocracias territoriales. En otras palabras, aquí uno se compromete evidente y deliberadamente en un terreno normativo; todo esfuerzo de cambio sustancial en esta dirección parece eminentemente deseable para vigorizar colectividades locales cuya acción es cada vez más rechazada por su población, no por falta de interés por las posturas políticas públicas. Entre los países occidentales, Francia es, sin duda junto con Gran Bretaña, el país donde los mecanismos de participación local de los ciudadanos se deberían diseñar de nuevo y reorganizar, inspirándose en la gama de dispositivos en vigor en el modelo centro-norte europeo. El riesgo del cesarismo en la alcaldía resultante de la fuerte legitimidad política del alcalde y de sus medios de acción propios podría rodearse como en otros países con sistema presidencial de gobierno local por un cierto número de medidas dirigidas a prevenir los excesos y a animar los contrapoderes: la introducción del referéndum, una duración del mandato reducida a cuatro años, una limitación estricta del cúmulo de cargos y posibilidades de destitución.

El grado de fragmentación de un sistema condiciona bastante su legibilidad, su comprensión y, por consiguiente, la capacidad de influencia ejercida por los ciudadanos. La reducción de la fragmentación constituye desde entonces una condición previa a todo programa de fortalecimiento de la democracia. La «modernización» de la política preconizada por Tony Blair permanecerá puramente superficial mientras perdure el mosaico de agencias, unidades, organismos y otros Quangos (Quasi-non governmental Organisations) que hacen bastante opaca la conducta de los asuntos locales para los ciudadanos británicos. La complejidad extrema de los circuitos de decisión no resulta ni en Francia ni en Gran Bretaña de la fluidez de la distinción entre lo público y lo privado; ésta está en primer lugar vinculada con la fragmentación territorial que logró despojar a las colectividades locales de una parte creciente de su esfera de influencia en beneficio de una miríada de organismos de cooperación intercomunal que directamente no rinden cuentas al pueblo sobre su actuación. El reto esencial que hoy debe afrontar el gobierno local francés reside en la necesaria adaptación de sus estructuras a las escalas diversificadas de la democracia. El futuro conjunto de reformas institucionales debería, por lo tanto, englobar una serie de niveles, como los de la metrópoli y del barrio, cuyo desarrollo político específico ha permanecido yermo durante años. 
- Conferencia impartida en el marco de las «IV Jornadas sobre temas contem. poríneos de Gobierno y Administración Local en España», celebradas en Madrid en los días 14.16 de junio de 2000, organizadas por el Consejo General Nacional de Colegios de Funcionarios de Administración Local con Habilitación de Carácter Nacional.

Aparece publicada en la revista CUNAL, No. 40 (septiembre de 2000).

** Chargé de Recherche au CNRS.

' En ln misma época, el mapa administrativo de Francia es de una claridad incom. parable (GODECHOT, 1951: Mapa I).

2 Rcficrase al estudio clásico de Heffer (1950).

${ }^{3}$ Varios administrativistas (Jean Rivero, Sabino CASSESE) y expertos en política francesa (Yves MéNY) también estudiaron estas prácticas de imitación y de mime. tismo institucionales.

${ }^{4}$ El perfcccionamiento pluridisciplinario de las «ciencias municipales» se mate. rializa bajo la República de Weimar por el incremento de actividades impulsadas por las asociaciones profesionales, las uniones de ciudades, los partidos políticos, las Universidades (por ejemplo, la de Berlín con su Instituto de Ciencias Municipales), y la multiplicación de publicaciones entre las cuales se encuentra una de sus obras maestras, el imponente y voluminoso «diccionario de bolsillo» dirigido por BRIX et al. (1918.1927).

'La admiración un poco ingenua de los prosélitos americanos por el buen y eficiente gobiemo "Made in Germany" se pone de manifiesto en una serie de artículos publicados a principios del siglo xx en la American Political Science Review; para ampliar este punto, ver el estimulante análisis del historiador NoLTE (1988), nsí como el de LENGER (1995).
' La sección «Current Municipal Affairs» de la American Political Science Review, en la cual el ejemplo alemán se volvía a dar como un leitmotiv después del cambio de siglo, se interrumpe en 1915.

7 Ver los testimonios citados por KaElBLE (1991) y también el estudio de SutCLIFFE (1981).

${ }^{8}$ La comparación de las evoluciones demográficas de algunas grandes ciudades es edificante: mientras que entre 1870 y 1910 , la población de Burdeos evoluciona de 200.000 a 250.000 habitantes, la de Lyon evoluciona de 320.000 a 460.000 y la de Toulouse de 125.000 a 150.000 , la de Leipzig pasa de 107.000 a 590.000 , la de Francfort de 91.000 a 415.000 y la de Nuremberg de 83.000 a 333.000 habitantes.

${ }^{9}$ Para ampliar conocimientos sobre esta proliferación de comités, comisiones, consejos y distritos especiales, ver BANFIELD y WILSON (1963).

${ }^{10}$ Según los resultados de un sondeo CLF-SOFRES (Le Monde, 19 de noviembre y 4 de diciembre de 1996).

"Según la feliz fórmula propuesta por KNOEPFEL y KISSLING-NäF (1993). THOENIG (1996: 141) evoca por su cuenta el desarrollo de una «acción colectiva co-cons. truida más allá de las decisiones políticas», «Poderes y contra-poderes locales: otorgar la democracia a los ciudadanos», en Instituto de la Descentralización, 1996. La descentralización en Francia. París: La Découverte: 131-142: 141.

${ }^{12}$ Quien, para apoyar su tesis, describe el poder creciente de la burocracia sobre la sociedad occidental de su época (WEBER, 1980).

${ }^{13}$ En julio de 1998, Sharpe (1998: 19) no se hacía ninguna ilusión: «nada de lo que el nuevo gobierno laborista ha emprendido en materia de gobierno local desde su acceso al poder sugiere cualquier diferencia verdadera con respecto al gobierno conservador que ha reemplazado».

\section{Bibliografia}

ALBA:K, Erik; Rose, Lawrence; StrŐmBERG, Lars, y StäHlBERG, Krister (1996), Nordic Local Govemment, Helsinki: The Association of Finnish Local Authorities.

ANDREw, Caroline, y GoLDSMrTH, Michael (1998), «From Local Government to Local Governance - and Beyond?», International Political Science Review, vol. 19, No. 2, April: 101-117.

Appleton, Lynn, y Hoffmann-Martinot, Vincent (1994), «City Workers and Fiscal Cutbacks: Cross-National Comparisons», en Carmel Corne (ed.), Research in Urban Policy. Vol. S. Local Administration in the Policy Process: An International Perspective, Greenwich, Conn.: Jai Press (avec): 193-229.

Ashili:y, Percy (1921), Le pouvoir central et les pouvoirs locaux (Angleterre, France, Prusse, États-Unis), Paris: Marcel Giard.

Banfield, Edward C., y Wilson, James Q. (1963), City Politics, New York: Vintage Books.

Brix, Josef; Lindemann, Hugo; Most, Otto; Preub, Hugo, y Súdexum, Albert, Handiörterbuch der Kommunalwissenschafien, Jena, 1918-1927, 6 volumes.

RoBert, Caro (1974), The Power Broker: Robert Moses and the Fall of New York, New York: Vintage.

Clark, Terry Nichols, y Hoffmann-Martinot, Vincent (1998), The New Political Culture, Boulder, Co.: Westview Press.

DelCaMp, Alain (1997), «Le modèle français de libre administration face aux autres modèles européens», Annuaire des Collectivités locales 1997, Paris: Litec: 73.109.
DelGADO, Irene; LOPEZ-NIETO, Lourdes, y LOPEZ, Eliseo (1998), «Functions and Duties of Funcionarios Directivos Locales (Local Chief Officers)», en Kurt Klaudi KLaUSEN y Annick MaGnier (eds.), The Anonymous Leader. Appointed CEO's in Western Local Government, Odense: Odense University Press: 238.252.

Dente, Bruno, y KJellberG, Francesco (eds.) (1988), The Dynamics of Institutional Change. Local Govermment Reorganization in Westerm Democracies, London: Sage: 89-129.

DUPRÉ, J. Stefan (1967), «Intergovernmental Relations and the Metropolitan Area, Paper No. 5, Centennial Study and Training Programme on Metropolitan Problems, Toronto.

Eisinger, Peter (1998), «City Politics in an Era of Federal Devolution», Urban Affairs Review, vol. 33, No. 3, January: 308-325.

Gabriel, Oscar W., y Hoffmann-Martinot, Vincent (sous la direction de) (1999), Démocraties urbaines. L'état de la démocratie dans les grandes villes de 12 pays industrialisés, Paris: L'Harmattan (Coll. Travaux et Recherches du GRALE).

GODECHOT, Jacques (1951), Les institutions de la France sous la Révolution et l'Empire, Paris: PUF.

GoldsmTrt, Mike (1995), «Autonomy and City Limits», en David JudGe, Gerry StOKER y Harold Wolman (eds.), Theories of Urban Politics, London: Sage: 228-252.

Heffter, Heinrich (1950), Die deutsche Selbstverwaltung im 19. Jabrbundert. Geschichte der Ideen und Institutionen, Stuttgart: K. F. Koehler. 
HESSE, Joachim Jens, y SHARPE, Lawrence J. (1991), «Local Government in International Perspective: Some Comparative Observations», en Joachim Jens HesSE (ed.), Local Government and Urban Affairs in Intemational Perspective, Baden-Baden: Nomos: 603-621.

HinTze, Otto (1962), Staat und Verfassung. Gesammelte Abbandlungen zur allgemeinen Verfassungsgeschichte, Göttingen: Vandenhoeck \& Ruprecht: 216-241.

HOFFMann-MarTinot, Vincent (1997), «Zentralisierung und Dezentralisierung», en Robert Picht, Vincent Hoffmann-Martinot, René Lasserre y Peter Theiner (Hrsg.) (1997), Fremde Freunde. Deutsche und Franzosen vor dem 21. Jabrbundert, München: Piper: 168-175.

Humes, Samuel (1991), Local Governance and National Power. A Worldwide Comparison of Tradition and Change in Local Government, Hemel Hempstead: Harvester Wheatsheaf.

KaELBLE, Hartmut (1991), Nachbarn am Rhein. Entfremdung und Annäberung der französischen und deutschen Gesellschaft seit 1880, München: C. H. Beck.

KJeLLBERG, Francesco (1995), «The Changing Values of Local Government», The Annals of the American Academy of Political and Social Sciences, No. 540, July: 40.50 .

KNoEPFEL, Peter, y Kussung.NÄF, Ingrid (1993), «Transformation öffentlicher Politiken durch Verräumlichung - Betrachtungen zum gewandelten Verhältnis zwischen Raum und Politik», en Adrienne HériTter (Hrsg.), Policy-Analyse: Kritik und Neuorientierung, Opladen: Westdeutscher Verlag (Politische Vierteljahressch. rift Sonderheft 24): $267-288$.

LE GALÈs, Patrick (1995), «Du gouvernement des villes à la gouvernance urbaine», Revue Française de Science Politique, vol. 45, No. 1, février: 57-95

LenGer, Friedrich (1995), «Großstädtische Eliten vor den Problemen der Urbanisierung. Skizze eines deutschamerikanischen Vergleichs 1870-1914», Geschichte und Gesellschaft, Heft 3: 313-337.

LjJPHART, Arend (1984), Democracies. Patterns of Majoritarian and Consensus Government in Twenty-One Countries, New Haven: Yale University Press.

Lowr, Theodore J. (1987), La Deuxième République des États-Unis: la fin du libéralisme, Paris: PUF.

Mabueau, Albert (1991), Le système local en France, Paris: Montchrestien.

MAuD, Sir John (1967), Comittee on the Management of Local Govermment, vol. 1, London: HMSO.

Merton, Robert K. (1965), Eléments de théorie et de méthode sociologique, Paris: Plon.

NoLte, Paul (1988), «Effizienz oder "self-government"? Amerikanische Wahrnehmungen deutscher Städte und das Problem der Demokratie 1900-1930», Die alte Stadt, Heft 3, 1988: 261-288.

PAGE, Edward C. (1991), Localism and Centralism in Europe, Oxford: Oxford University Press.
PAGE, Edward C., y GoldSMITH, Mike (1987), Central and Local Govemment Relations, London: Sage.

Prud'Homme, Rémy (1994), «La France, pays le plus décentralisé d'Europe?», Le Monde, 17 mai: IX

PUtzGer, F. W. (1965), Historischer Weltatlas, Bielefeld, Berlin, Hannovre: Vel. hagen und Kalsing (première édition en 1877).

Rodriguez Álvarez, José Manuel (1996), «Las juntas de distrito en las grandes ciudades españolas. Un estudio comparado de su organización y de su regulación positiva», Actualidad Administrativa, XXXI, 27, 1-7 julio: 525.588.

Sharpe, Lawrence J. (1998), «British Centralism Revisited», Communication au Congrès Annuel de l'American Political Science Association, Boston, 3.6 sep tembre, $21 \mathrm{p}$.

- (1988), «Local Government Reorganization: General Theory and UK Practice», en Bruno DenTE y Francesco KJELLBERG (eds.), The Dynamics of Institutional Change. Local Govermment Reorganization in Westerm Democracies, London: Sage: 89-129.

- (1970), «Theories and values of local government», Political Studies, vol. XVIII, No. 2: $153-174$.

SHAw, Albert (1985), Municipal Govermment in Continental Europe, New York.

Sutcuffe Antony (1981), Towards the Planned City: Germany, Britain, the United States and France, 1780-1914, Oxford: Blackwell.

ThoEnIG, Jean-Claude (1996), «Pouvoirs et contre-pouvoirs locaux: rendre la démocratie aux citoyens», en Institut de la Décentralisation, 1996, La décentralisation en France, Paris: La Découverte: 131-142.

TocQueviles, Alexis de (1967), L'ancien régime et la Révolution, Paris: Gallimard (Coll. Idées).

VANDEU, Luciano (1991), Pouvoirs locaux, Paris: Economica

WEBER, Max (1980), «Parlment und Regierung und Regierung im neugeordneten Deutschland. Zur politischen Kritik des Beamtentums und Parteiwesens», en Gesammelte politische Schriften, Tübingen: J. C. B. Mohr: 306-443.

WELls, Roger Hewes (1932), German Cities. A Study of Contemporary Municipal Politics and Administration, Princeton: Princeton University Press.

WICKW'AR, W. Hardy (1970), The Political Theory of Local Govermment, Columbia, South Carolina: University of South Carolina Press.

WRIGHT, Vincent (1993), «Royaume-Uni: Whitehall et le local government à l'épreuve du thatchérisme», en L'adminsitration territoriale en Europe. Allemagne, Espagne, Italie, Pays-Bas, Royaume-Uni. Paris: La Documentation Française (Coll. Dossiers et Débats): 95-117.

YATES, Douglas (1977), The Ungovernable City: The Politics of Urban Problems and Policy Making, Cambridge, Mass.: The MIT Press. 